\title{
Cyanine Masking: A Strategy to Test Functional Group Effects on Antibody Conjugate Targeting
}

Ek Raj Thapaliya, ${ }^{1}$ Syed Muhammad Usama, ${ }^{1}$ Nimit L. Patel, ${ }^{2}$ Yang Feng, ${ }^{3}$ Joseph D. Kalen, ${ }^{2}$ Brad St. Croix, ${ }^{3}$ Martin J. Schnermann ${ }^{1 *}$

${ }^{1}$ Chemical Biology Laboratory, Center for Cancer Research, National Cancer Institute, Frederick, Maryland 21702, United States

${ }^{2}$ Small Animal Imaging Program, Frederick National Laboratory for Cancer Research, Leidos Biomedical Research Inc., Frederick, Maryland 21702, United States

${ }^{3}$ Tumor Angiogenesis Unit, Mouse Cancer Genetics Program (MCGP), National Cancer Institute, NIH, Frederick, Maryland 21702, United States

Email: martin.schnermann@nih.gov

\begin{abstract}
Conjugates of small molecule and antibodies are broadly employed diagnostic and therapeutic agents. Appending a small molecule to an antibody often significantly impacts the properties of the resulting conjugate. Here we detail a systematic study investigating the effect of various functional groups on the properties of antibody-fluorophore conjugates. This was done through the preparation and analysis of a series of masked heptamethine cyanines (CyMasks) bearing amides with varied functional groups. These were designed to exhibit a broad range of physical properties, and include hydrophobic (-NMe $)$, pegylated (NH-PEG-8 or NH-PEG-24), cationic (NH- $\left.\left(\mathrm{CH}_{2}\right)_{2} \mathrm{NMe}_{3}{ }^{+}\right)$anionic $\left(\mathrm{NH}-\left(\mathrm{CH}_{2}\right)_{2} \mathrm{SO}_{3}{ }^{-}\right)$, and zwitterionic $(\mathrm{N}-$ $\left.\left.\left(\mathrm{CH}_{2}\right)_{2} \mathrm{NMe}_{3}^{+}\right)-\left(\mathrm{CH}_{2}\right)_{3} \mathrm{SO}_{3}^{-}\right)$variants. The CyMask series was appended to tumor targeting monoclonal antibodies (mAbs) and analyzed for effects on tumor targeting, clearance and non-specific organ uptake. Among the series, zwitterionic and cationic dye conjugates showed the highest tumor-to-background ratio (TBR), although the latter also exhibited an elevated liver-to-background ratio (LBR). Overall, these studies provide a strategy to test the functional group effects and suggest that zwitterionic substituents are an attractive strategy to mask hydrophobic payloads, with the potential to improve the properties of bioconjugates in vivo.
\end{abstract}

KEYWORDS. antibody fluorophore conjugates, in vivo optical imaging, drug delivery, fluorescence guided surgery, tumor imaging 


\section{TOC GRAPHIC}

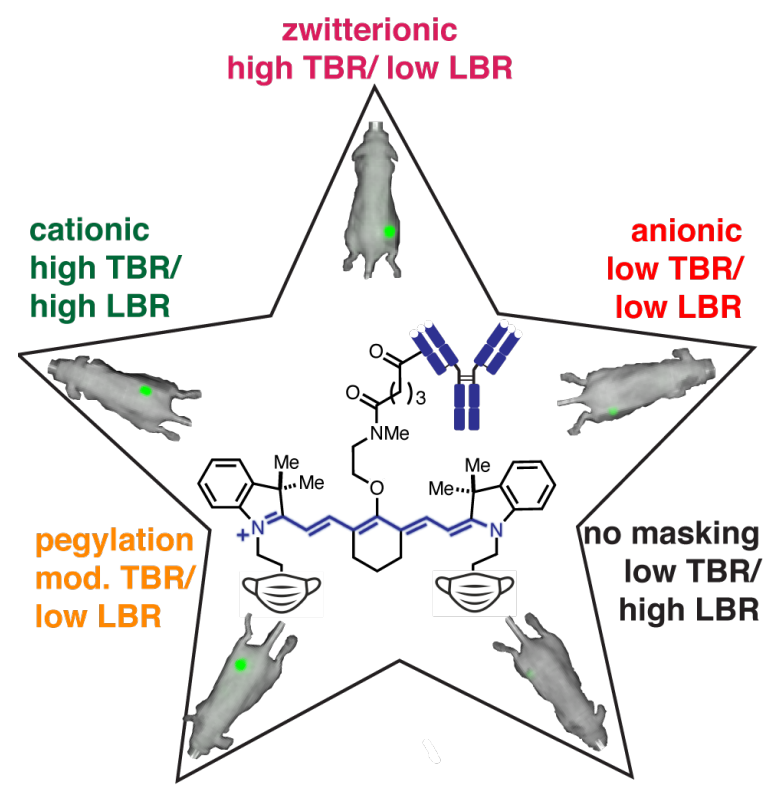

\section{INTRODUCTION}

Conjugates of monoclonal antibodies (mAbs) and small molecules are indispensable tools for diagnostic and therapeutic applications. While long used for various cellular imaging applications (i.e. immunolabeling), the last decade has seen significant progress in the translation of mAb conjugates into clinical settings. For example, conjugates of fluorescent molecules and mAbs have emerged as powerful tumor imaging agents for fluorescence guided surgery. ${ }^{1,2}$ In the context of therapeutics, antibody drug conjugates (ADCs) harness the specificity of antibodies to selectively deliver potent payload molecules. ${ }^{3}$ Despite significant progress validating these approaches, significant challenges remain. In particular, many small molecule payloads interfere with the intrinsic targeting and clearance of the parent antibody. ${ }^{4-6}$ Various strategies are being explored to circumvent this issue. These include homogenous labeling strategies, which have been explored extensively for ADCs. While such strategies improve certain in vivo properties, they increase the complexity of the labeling process. ${ }^{7-9}$ For optical probes, the use of highly charged, persulfonated fluorophores is a long established strategy designed to address the issue of fluorophore aggregation on the protein surface. ${ }^{10}$ This strategy led to the creation of numerous broadly-used fluorophores, including the "Cy" and "Alexa Fluor" series. While these probes are optimized for in vitro efforts, more recent results from our group and others have shown that the highly charged, but net neutral (i.e. zwitterionic) fluorophores can improve the targeting of mAbs in vitro and in vivo. ${ }^{16}$ 
A critical, still outstanding question is what functional group can best mitigate the impact of small molecule labeling on mAb targeting? Here, we pursue a strategy centered on comparing the antibody conjugates of a series of modified near-infrared (NIR) fluorescent dyes. While intrinsically hydrophobic, these molecules can be synthetically modified with polar functional groups. Several prior studies, including from our group, have examined the impact of modifications on the in vivo properties of $\mathrm{mAb}$-fluorophore conjugates. ${ }^{11-16,17,18,19-21}$ While these prior studies provided key insights, they are not systematic from a "functional-group" perspective making it hard to draw larger lessons (See Figure S1 for previously tested molecules). Here we address this issue with single point alterations to substituents distal to the cyanine scaffold. We hypothesize that this approach will provide insights that can broadly inform the design of various bioconjugates.

Below we detail the synthesis and evaluation of a series of masked heptamethine cyanines (CyMasks) and their antibody conjugates. These probes enable the unbiased assessment of chemical masking strategies on tumor targeting and off-target accumulation of mAb conjugates. In line with prior results, we find that the most hydrophobic probe exhibits the most non-selective in vitro uptake and the lowest in vivo tumor targeting. We also find that anionic and cationic masking groups lead to increased dye aggregation and reduced tumor signal. Notably, pegylated probes, which have been broadly applied in other contexts, ${ }^{22-27}$ exhibit excellent in vitro uptake, but reduce in vivo tumor targeting. By contrast, zwitterionic probes, bearing both quaternary ammonium and sulfonate functional groups, exhibit excellent in vitro and in vivo properties. We hypothesize that the combination of highly charged, but net neutral, substituents may offer significantly improved biophysical properties with implications to a range of bioconjugates.

\section{RESULTS AND DISCUSSION}

\section{Synthesis and Characterization of CyMask and mAb Conjugates}

In designing the CyMask series, we sought to examine a range of polar substituents and chose representative zwitterionic, cationic, anionic, pegylated and hydrophobic functional groups. Specifically, we synthesized six CyMask dyes containing amides substituted with PEG-8, PEG-24, $N$-ethyl-sulfonate (Sulfo), $N$-ethyl-trimethyl-ammonium (Quat), $N$-trimethyl-propyl-ammonium- $N$-butyl-sulfonate (Zwit) and, a hydrophobic derivative, methylamine (Me). As shown in Scheme 1, the CyMask-NHS esters were synthesized from the known precursor (1) using our previously reported Smiles rearrangement method. ${ }^{11}$ Compound 1 underwent substitution with $\mathrm{N}$-methyl-ethanolamine in $\mathrm{MeCN}$ at $80{ }^{\circ} \mathrm{C}$ to obtain 2 . The subsequent Smiles rearrangement $\left(\mathrm{C}^{\prime}-N\right.$ to $\mathrm{C} 4{ }^{\prime}-O$ alkylation $)$ reaction was carried out using an initial TFA induced rearrangement, followed by electrophilic trapping in THF in the presence of $\mathrm{NaHCO}_{3}$ at $50{ }^{\circ} \mathrm{C}$ to give methyl ester $\mathbf{3}$. This common precursor $\mathbf{3}$ was used to couple with primary amines $\mathbf{4 a - f}$ to give amides 5a-f and subsequent saponification with $\mathrm{LiOH}$ provided the free carboxylic acids (6a-f). We compared the 
photophysical properties of all six CyMask carboxylic acids (6a-f) and found similar optical properties in PBS pH 7.4 and 10\% FBS (Table 1, Figure S2,S3) across this series and relative to other C4'-O-linked heptamethine cyanines. ${ }^{11-16}$ These observations confirm the minimal impact of the distal modification on the optical properties of the free molecules.

Scheme 1: Synthesis of compounds in CyMask series and conjugation with Panitumumab.
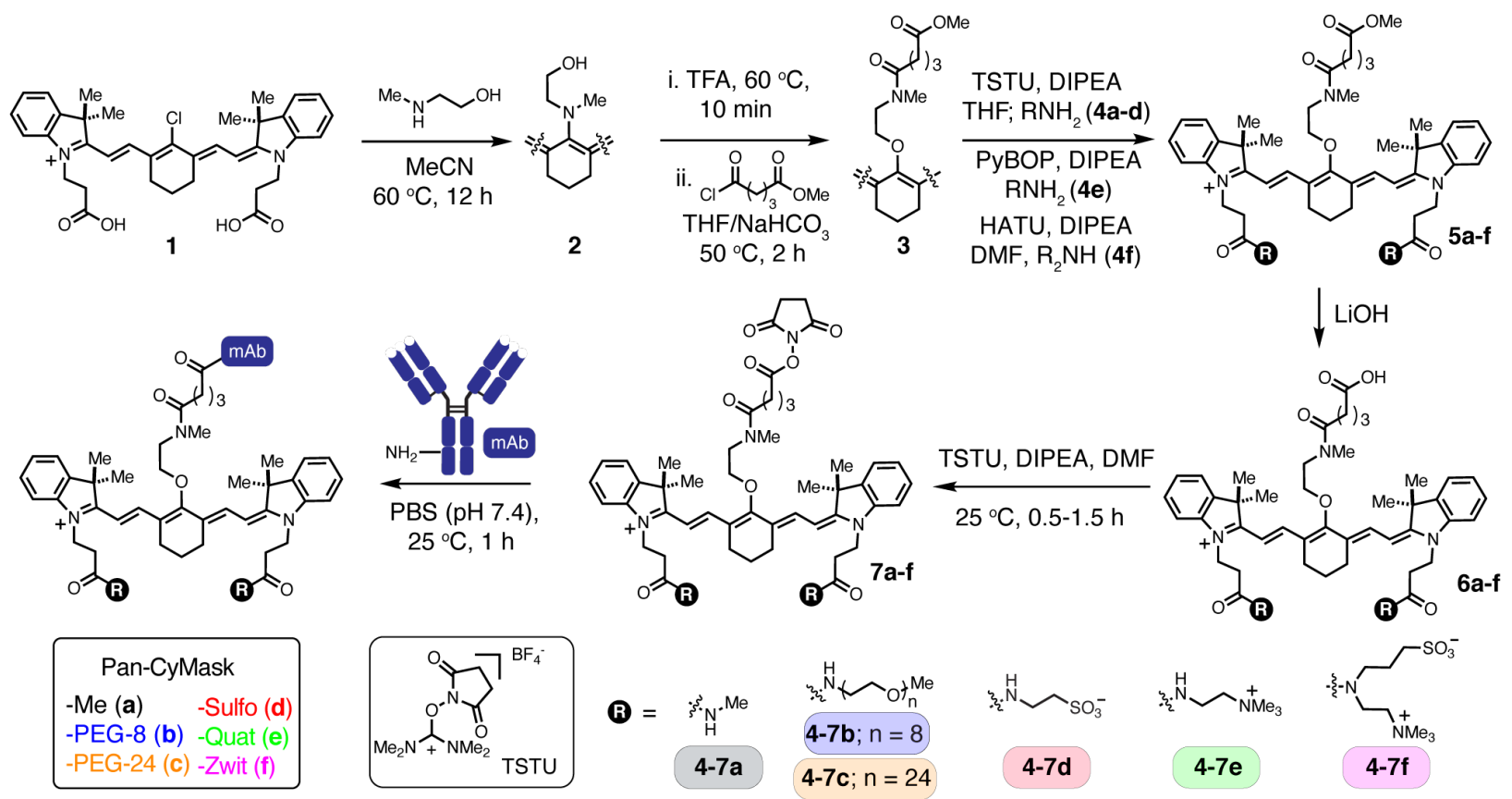

Table 1: Key Spectroscopic Properties.

\begin{tabular}{|c|c|c|c|c|c|c|}
\hline CyMask- $\mathrm{CO}_{2} \mathrm{H}$ & $\begin{array}{c}\lambda_{\text {max,abs }} \\
(\mathrm{nm})\end{array}$ & $\begin{array}{c}\lambda_{\text {max }, \mathrm{em}} \\
(\mathrm{nm})\end{array}$ & $\Phi_{\mathrm{F}}$ & $\begin{array}{c}\varepsilon^{\mathrm{a}} \\
\left(\mathrm{M}^{-1} \mathrm{~cm}^{-1}\right)\end{array}$ & $\begin{array}{c}\text { brightness } \\
\left(\varepsilon \times \Phi_{\mathrm{F}}\right)\end{array}$ & $\begin{array}{l}\text { net surface } \\
\text { charge }\end{array}$ \\
\hline $\begin{array}{c}\text { CyMask-Me- } \\
\mathrm{CO}_{2} \mathrm{H}(\mathbf{6 a})\end{array}$ & 766 & 781 & 0.14 & 161000 & 22,500 & 0 \\
\hline $\begin{array}{c}\text { CyMask-PEG-8- } \\
\mathrm{CO}_{2} \mathrm{H}(\mathbf{6 b})\end{array}$ & 766 & 781 & 0.13 & 203000 & 26,400 & 0 \\
\hline $\begin{array}{l}\text { CyMask-PEG- } \\
24-\mathrm{COOH}(\mathbf{6 c})\end{array}$ & 766 & 781 & 0.15 & 182300 & 27,500 & 0 \\
\hline $\begin{array}{l}\text { CyMask-Sulfo- } \\
\mathrm{CO}_{2} \mathrm{H}(\mathbf{6 d})\end{array}$ & 764 & 780 & 0.11 & 174000 & 19,000 & -2 \\
\hline $\begin{array}{l}\text { CyMask-Quat- } \\
\mathrm{CO}_{2} \mathrm{H}(\mathbf{6 e})\end{array}$ & 764 & 780 & 0.12 & 184000 & 22,000 & +2 \\
\hline $\begin{array}{c}\text { CyMask-Zwit- } \\
\mathrm{CO}_{2} \mathrm{H}(\mathbf{6 f})\end{array}$ & 764 & 780 & 0.11 & 184000 & 20,240 & 0 \\
\hline
\end{tabular}

a. Molar absorption coefficient of all dyes was measured in 1:1 MeOH-PBS pH 7.4. 
We then sought to examine the impact of the masking functional group on the properties of $\mathrm{mAb}$ conjugates. The carboxylic acids 6a-f $\left(\mathrm{CyMask}-\mathrm{CO}_{2} \mathrm{H}\right)$ were converted to CyMask-NHS esters (7a-f) using $N, N, N^{\prime}, N^{\prime}$-tetramethyl-O-(N-succinimidyl) uronium tetrafluoroborate (TSTU) and used in the bioconjugation step. We choose to first generate conjugates with Panitumumab (Pan), an anti-EGFR FDAapproved monoclonal antibody, which has been used extensively by us and others for imaging applications. ${ }^{11-16}$ All six NHS esters were reacted with panitumumab (Pan) in 50 mM PBS pH 7.4 with molar excesses of 3, 6 and 10X to obtain the lysine labeled Pan conjugates with a degree of labeling (DOL) of $1,2,3( \pm 0.3)$, respectively. Two purification methods were applied to remove unlabeled probe. The dye conjugates were passed through a spin desalting column and stored overnight at $4{ }^{\circ} \mathrm{C}$ to dissociate noncovalently bound free dyes. The resulting solutions were purified a second time by passing through a desalting column eluting with PBS pH 7.4. All conjugates provided homogenous solutions with stable absorption spectra over a several month timeframe.

The photophysical properties of these mAb-CyMask conjugates were analyzed in detail. The absorbance spectra were recorded in PBS pH 7.4 (Figure 1). While displaying nearly identical absorbance maxima, significant variation in the H-aggregate peak at $700 \mathrm{~nm}$ (Figure 1a insert) was observed across the various conjugates in PBS, but not in denaturing conditions (1:1 PBS:MeOH, Figure S5). This peak, which results from cyanine dimerization on the protein surface, is a well characterized consequence of protein labeling. ${ }^{28-30}$ The magnitude of the H-aggregate was found to be dependent on both the probe and the DOL. ${ }^{31-33}$ As a convenient means to quantify these effects, we examined the ratio of the absorbance values 766 (monomer) and 700 (dimer) nm (Figure 1a-d). Across the series, the values decrease along series Sulfo $>$ Me $>$ Zwit $>$ PEG-8 $>$ Quat $>$ PEG-24. Notably, PEG-24 provided almost complete inhibition of Haggregate formation, as noted elsewhere. ${ }^{23,34}$ The observation that sulfonated substituents led to the most substantial $\mathrm{H}$-aggregate formation is somewhat surprising. Prior results clearly indicate that sulfonates appended to the indolenine heterocycles improve the properties of the resulting mAb conjugates. ${ }^{29,30,35,36}$ However, these results suggest that distal sulfonates are not sufficient to inhibit H-aggregation, and may even induce formation. Lastly, we evaluated the quantum yield $\left(\Phi_{\mathrm{F}}\right)$ of the mAb conjugates at DOL 3. Notably, $\Phi_{\mathrm{F}}$ of thee conjugates did not vary dramatically $(4.8 \%$ to $7.5 \%$ ) in $\mathrm{PBS} \mathrm{pH} 7.2$ (Figure 1e). Additionally, we observe little correlation between $\Phi_{\mathrm{F}}$ with either H-aggregation or the in vivo results described below. These observations suggest that the photon output of the fluorophore-mAb conjugates is relatively insensitive to the CyMask functional group, which simplifies the analysis of the in vivo data reported below. 
a. Pan-CyMask -Me -PEG-8 -Sulfo -PEG-24 -Quat -Zwit
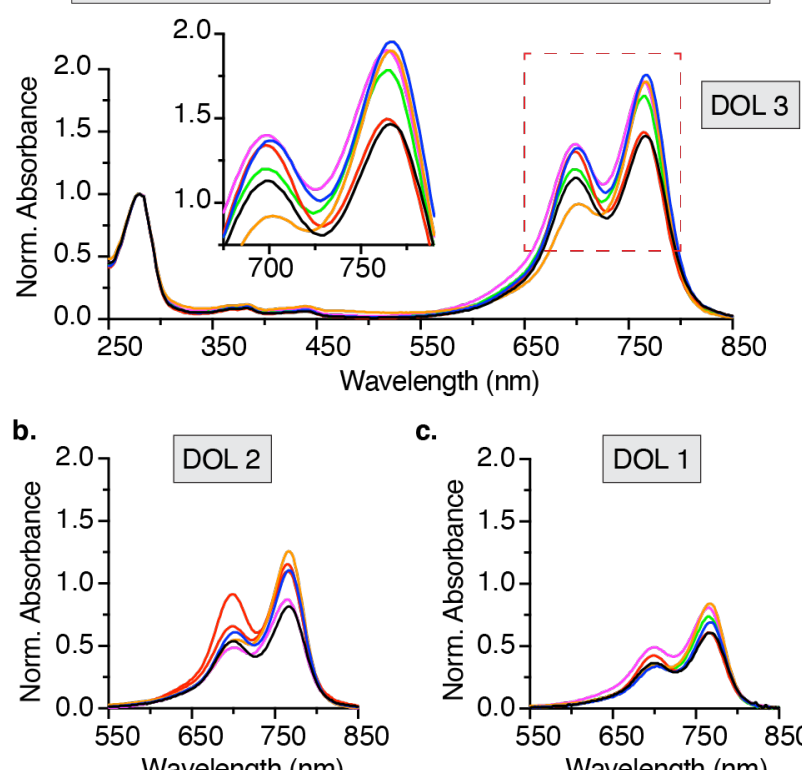

c.
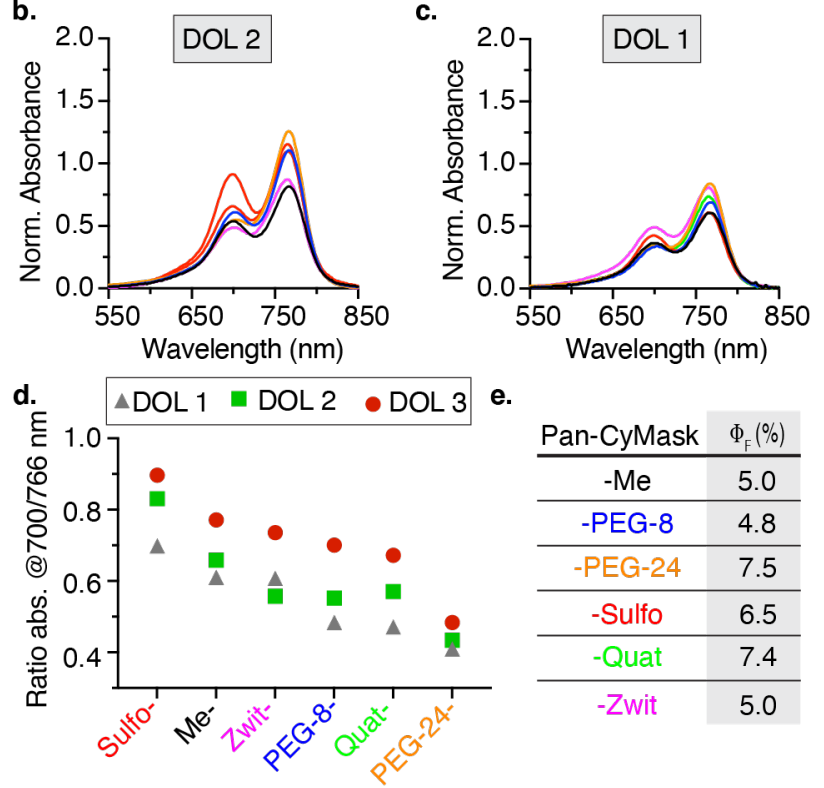

Figure 1. Characterization of Pan-CyMask conjugates. a. Normalized absorption of Pan-CyMask conjugates (DOL 3, PBS pH 7.2). Zoomed in spectra is depicted in inset. b. Normalized absorption of PanCyMask conjugates (DOL 2, PBS pH 7.2). c. Normalized absorption spectra of Pan-CyMask (DOL 1, PBS $\mathrm{pH}$ 7.2). d. Aggregation ratio (absorbance ratio at 700/766 nm) of Pan-CyMask conjugates at DOL 1, 2 and 3 , calculated from absorption spectra. e. $\Phi_{\mathrm{F}}$ (measured by relative method) Pan-CyMask conjugates (DOL 3, PBS pH 7.2).

\section{Comparison of Panitumumab-CyMask Conjugates}

We sought to characterize the impact of the CyMask modifications on tumor targeting and biodistribution of these agents. These studies were carried out using athymic nude female mice bearing EGFR+ MDAMB-468 xenografts implanted subcutaneously in the right flank $\left(5 \times 10^{6}\right.$ cells, $\mathrm{n}=5$ per group $) .{ }^{16}$ The mice were injected with $50 \mu \mathrm{g}$ of the Pan-CyMask conjugates (DOL 3). Fluorescence images were obtained using an IVIS imaging system before injection and at 4, 24, 48, 72 and $168 \mathrm{~h}$ post injection. As early as $4 \mathrm{~h}$, all the conjugates showed significant tumor signal, which increased over the next 7 days (Figure 2a, S6-7). After 7 days, the highest radiance fluorescence intensity was observed with the Zwit- and Quat- conjugates, with values that are $\sim 5.5$ and 5.0-fold higher compared to Me- conjugate, respectively. Analysis of the 
tumor-to-background ratio $(\mathrm{TBR})$ indicates a rank order $\mathrm{Zwit} \approx$ Quat $>$ PEG-24 $>$ Sulfo $\approx \mathrm{PEG}-8 \approx \mathrm{Me}$ 1-week p.i. (Figure 2b-c). While the fluorescence signal in most healthy organs remain low, significant background uptake was observed in liver, specifically for cationic and anionic dye conjugates, with strongest signal at the $4 \mathrm{~h}$ time point (Figure 2d, S6-7). Of note, the in vivo imaging data was confirmed in subsequent ex vivo study using Pan-CyMask-Zwit and Pan-CyMask-Me conjugates, where mice ( $\mathrm{n}=3$ per group) were analyzed ex vivo at $48 \mathrm{~h}$ p.i. (Figure S8). Ex vivo histopathological analysis of tumor slices injected with Pan-CyMask-Zwit and Pan-CyMask-Me showed heterogenous near infrared signal throughout the tumor with highest signal around vasculature (Figure 2e, S9). In the tissue samples, we observed $\sim 2 \mathrm{X}$ higher fluorescent labeling in tumors with Pan-CyMask-Zwit ( 20-30\%) as compared to Pan-CyMask-Me ( $\sim 10-20 \%)$. Overall, these results indicate the zwitterionic conjugates outperform the charged conjugates (Sulfo and Quat) with respective to liver uptake. Additionally, the zwitterionic conjugates improved mAb tumor uptake relative to hydrophobic, anionic and pegylated conjugates.

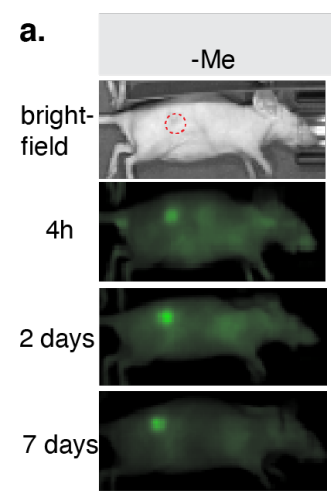

b.

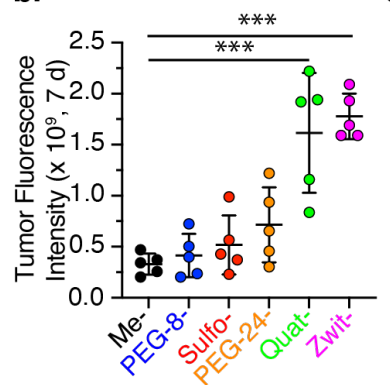

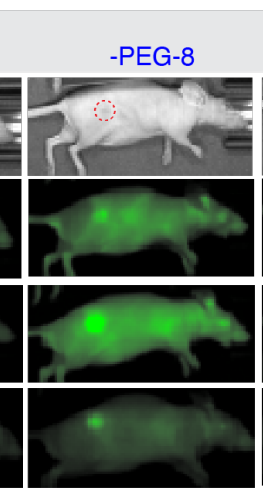

c.

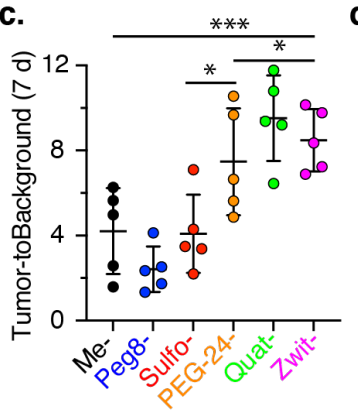

Pan-CyMask

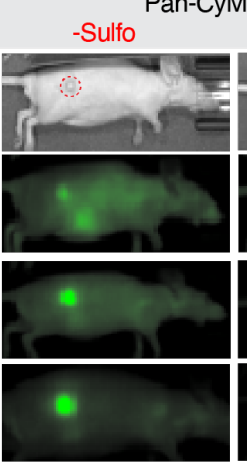

d.

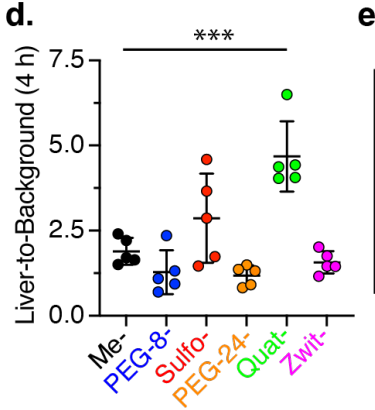

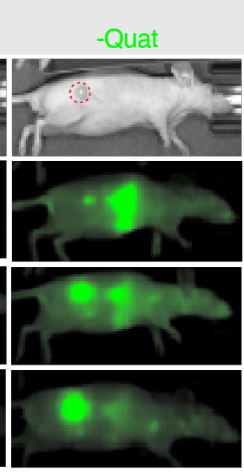

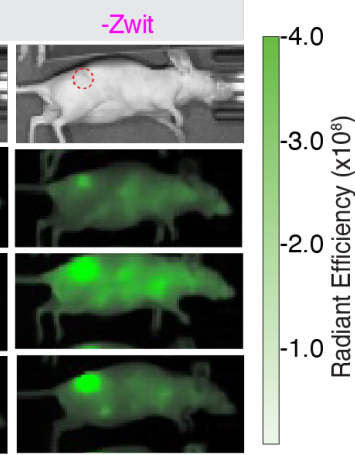

e.

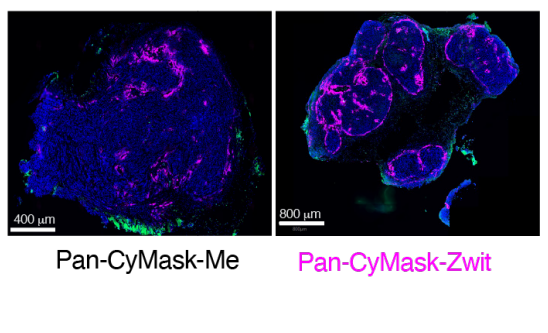

Figure 2. In vivo and ex-vivo fluorescence imaging of MDA- MB-468 xenograft tumor bearing mice injected with $50 \mu \mathrm{g}$ of each Pan-CyMask conjugates at DOL 3. a. In vivo fluorescence images (right dorsum) at pre-injection, and $4 \mathrm{~h}, 2$ days and 7 days post-injection (p.i.). b. Tumor signal (total radiant efficiency normalized to tumor size), c. tumor to background ratio, d. liver to background ratio of MDAMB-468 tumor-bearing mice injected with $50 \mu \mathrm{g}$ of six Pan-CyMask conjugates at DOL 3. Statistical analysis was performed between groups at 7 days using Student's t-test. * p-value $\leq 0.05, * * *$ p-value $\leq$ 0.001. e. Representative histopathological images of tumor tissue sections ( $48 \mathrm{~h}$, post injection) with PanCyMask-Me and Pan-CyMask-Zwit. The image is pseudo colored: pink (near infrared channel;Cy7), blue (DAPI) and green (autofluorescence). 
We then studied the cellular uptake of these fluorophore conjugates in EGFR+ (MDA-MB-468) or EGFR(MCF-7) cell lines. Epifluorescence microscopy demonstrated the high specific uptake of these dye conjugates in MDA-MB-468 cells compared to the control cells line MCF-7, when incubated with the same concentration of Pan-CyMask conjugates and incubation time $(250 \mu \mathrm{g} / \mathrm{mL}, 7 \mathrm{~h})$ (Figure 3a). This approach indicates similar cellular uptake of all six Pan-CyMask conjugates. We quantified these differences in more detail by determining an apparent binding constant $\left(\mathrm{EC}_{50}\right)$ using flow cytometry for three of the conjugates. The Pan-CyMask-PEG-24 conjugate showed slightly lower binding affinity $\left(\mathrm{EC}_{50}=7.6 \mathrm{nM}\right)$ compared to the Pan-CyMask-Zwit- $\left(\mathrm{EC}_{50}=4.5 \mathrm{nM}\right)$ or Pan-CyMask-Me $\left(\mathrm{EC}_{50}=6.9 \mathrm{nM}\right)$ (Figure 3b). Overall, these data studies suggest modest differences in in vitro cellular uptake between the CyMask series, and suggest that in vivo differences are largely due to altered clearance.

Next we investigated a potential for hepatic clearance pathway using an in vitro cellular model. Prior work examining the uptake of ADCs and other conjugates has revealed a critical role for stellate macrophages, or Kupffer cells, in mediating the uptake and clearance of bioconjugates labeled with hydrophobic payloads. ${ }^{37,38}$ To study the effect of the masking group on dye conjugates with respect to the non-specific uptake, we examined the uptake of these dye conjugates in rat Kupffer cells using flow cytometry. ${ }^{38}$ After incubation of Pan-CyMask conjugates with rat Kupffer cells for $24 \mathrm{~h}$, the most hydrophobic dye conjugate, Pan-CyMask-Me, exhibited increased uptake compared to other conjugates (Figure 3c). Notably, irrespective of the nature of the masking group, more hydrophilic dye conjugates showed similar non-specific uptake by Kupffer cells. These results are in line with the prior observations suggesting a role for Kupffer cells in the uptake of hydrophobic small molecule-mAb conjugates, but suggest that additional mechanisms maybe be at play for the high uptake of the positively charged PanCyMask-Quat conjugate in vivo. 


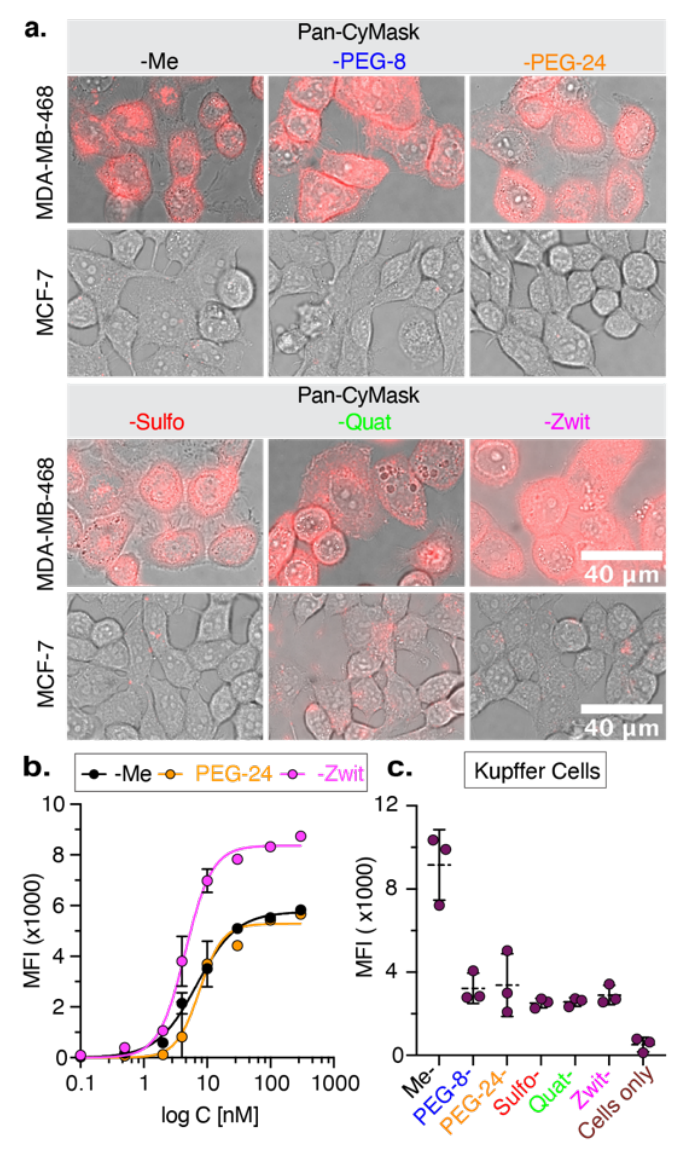

Figure 3. In vitro studies of Pan-CyMask conjugates in MDA-MB-468 (EGFR+), MCF-7 (EGFR-) and Kupffer cells. a. Epifluorescence imaging of cells after $7 \mathrm{~h}$ incubation of Pan-CyMask conjugates (250 $\mu \mathrm{g} / \mathrm{mL}$ ) for MDA-MB-468 (top row) and MCF-7 (bottom row). b. Binding affinity of Pan-CyMask conjugates in MDA-MB-468 cells. Cells were incubated with CyMask-Pan conjugates (0.1-0.3 $\mu \mathrm{M})$ at ice bath for $1 \mathrm{~h}$ in PBS pH 7.4 with $1 \mathrm{mg} / \mathrm{mL}$ of BSA containing $0.01 \%$ sodium azide and fixed. Mean Fluorescence Intensity (MFI $\pm \mathrm{SD}, \mathrm{n}=3$ ) was measured by flow cytometry. $\mathbf{c}$. Non-specific uptake of mAb conjugates in Kupffer cells. Cells were incubated with Pan-CyMask conjugates $0.1 \mathrm{mg} / \mathrm{mL}$ at $37^{\circ} \mathrm{C}$ for 24 $\mathrm{h}$ in serum-containing media, MFI $\pm \mathrm{SD}(\mathrm{n}=3)$ was measured by flow cytometry.

\section{Comparison of anti-CD-276 mAb-CyMask Conjugates}

To test the generality of these observations, we applied CyMask with a fully-human anti-CD276 (B7 homolog H3, B7H3) antibody that binds both mouse CD276 and human CD276 with similar affinity. ${ }^{39,40}$ This target is overexpressed in the cancer cells and tumor neovasculature of multiple solid tumor types, and this antibody has been applied to create potent ADCs. ${ }^{39-44}$ For the in vivo studies we chose to compare the effects of positive charge (Quat), no charge (Me) and net neutral charge (Zwit) CyMask on tumor targeting and clearance. The conjugates were injected intravenously into mice bearing 200-250 $\mathrm{mm}^{3}$ JIMT-1 breast tumors grown orthotopically in the mammary fat pad. The tumor fluorescence intensity and TBR was highest for the m276-SL-CyMask-Zwit (10.2) after 7 days (Figure 4a-b, S10-11). These studies provide additional evidence that zwitterionic masking can improve the properties of $\mathrm{mAb}$ conjugates. 

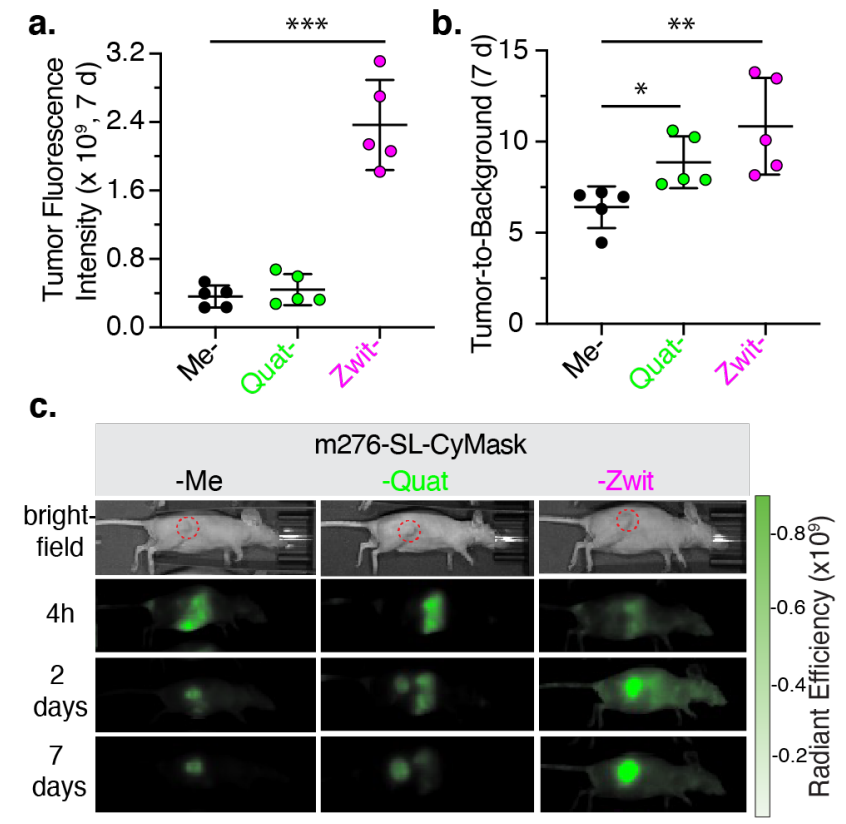

Figure 4. a. Quantification of tumor uptake of m276-SL-CyMask-Me, Quat and Zwit conjugates (50 $\mu \mathrm{g}$; DOL 3) in JIMT-1 tumors after $168 \mathrm{~h}$. b. Tumor-to-Background ratio at $168 \mathrm{~h}$ post injection. C. IVIS images at 4 h, 2 days and 7 days post injection. Tumor are highlighted in red dotted circles. Statistical analysis was performed between groups at $168 \mathrm{~h}$. Data points are displayed as mean $\pm \mathrm{SD}$, and the p-values were evaluated by the Student's t-test $(* \mathrm{p}$-value $\leq 0.05, * * \mathrm{p}$-value $\leq 0.01, * * * \mathrm{p}$-value $\leq 0.001)$.

\section{Conclusion}

In the studies outlined above, we detail an unbiased comparison of charge masking functional groups on the in vivo targeting properties of mAb-fluorophore conjugates. These studies reveal that zwitterionic and cationic shielding outperform pegylated, anionic, and hydrophobic conjugates with respect to tumor uptake. Furthermore, cationic shielding leads to the highest off-target liver uptake at early imaging time points. Notably, significant in vitro non-specific uptake by Kupffer cells occurs with the hydrophobic derivative, but not the charged or pegylated conjugates. In total, these results suggest the zwitterionic shielding groups may offer the optimal combination of excellent targeting and minimal off-target uptake. These results that align with prior studies from our group and others, which found zwitterionic heptamethine cyanines exhibit improved tumor uptake when compared to conventional persulfonated heptamethine cyanines. ${ }^{16,17,45}$

These observations complement prior work to optimize the in vivo properties of therapeutic protein and nano-material modalities. In particular, extensive efforts have investigated the impact of $\mathrm{mAb}$ sequence modifications on clearance and tumor targeting. The general theme to emerge from these efforts is that cationization and anionization - the introduction of positively and negatively charged amino acids, respectively - both increase plasma clearance rate, albeit through different mechanisms. ${ }^{46}$ Cationization 
generally increases tissue uptake, which can be advantageous for solid tumor uptake, but also leads to increased uptake in off-target organs. ${ }^{47}$ By contrast, anionization decreases tissue uptake due to increased whole-body (including blood) clearance through enhanced hepatic clearance. ${ }^{46}$ In general, these studies have settled on the notion that the isoelectric point (i.e. the $\mathrm{pH}$ at which the protein is net neutral) of native antibodies, which is typically between $7-8$, is preferred. While efforts to chemically introduce charged functional groups, as we have done here, are rare, extensive efforts have examined the impact of pegylation strategies. $^{23,34,47-51}$ While offering significant benefits with respect to plasma half-life, this approach increases the size of protein significantly with consequent impacts on binding interactions. ${ }^{52-55}$ Additionally, particularly when appended to long half-life proteins, such as mAbs, there is a potential for antibody mediated immune responses. ${ }^{56-58}$

Complementing efforts to augment the properties of proteins, the nanomaterials community has extensively studied the impact of charge and polarity as passivation strategies to improve the properties of otherwise hydrophobic species. In this context, there is significant evidence that zwitterionic functional groups reduce nonspecific adsorption at the particle/liquid interface. ${ }^{37,59}$ The resulting decrease in nonspecific interactions leads to reduced off-target uptake in various contexts. While, the exact mechanism of this effect isn't entirely clear, previous studies have suggested a combination of charge shielding, minimization of membrane penetration, and protein stabilization. ${ }^{60}$

Here we introduce a series of optical probes that enable the quantitative assessment of functional group effects on mAb-targeting in vivo. These results suggest that zwitterionic functional groups - which are highly charged, but net neutral modifications - may represent an important addition to the mAbbioconjugate landscape. This strategy, which maintains the original charge profile of the parent protein, and simultaneously introduces a highly charged functional group, may represent a promising approach to mask the undesirable hydrophobicity of drug-conjugates in the circulation. Future studies will investigate the potential impact of these modification in homogeneous $\mathrm{mAb}$ conjugates, where we hypothesize that charge will also play a significant role. ${ }^{61,62}$ Additionally, we suggest that the incorporation of such zwitterionic functional groups into otherwise hydrophobic therapeutic payloads may have significant promise. Studies toward this goal are underway in our group, and will be reported in due course.

\section{ASSOCIATED CONTENT}

Supporting Information

This material is available free of charge via the internet at http://pubs.acs.org. The supporting information contains synthesis procedures, characterization of CyMask probes, key intermediate compounds, photophysical properties of CyMask probes, details of in vitro and in vivo experiments and supporting figures and tables. 


\section{AUTHOR INFORMATION}

*Email: martin.schnermann@nih.gov

\section{ACKNOWLEDGMENTS}

This work was supported by the Intramural Research Program of the National Institutes of Health (NIH), NCI-CCR. It was also supported by an NCI CCR FLEX Program Synergy Award (to M.S. and B.S.C.) and a Congressionally Directed Medical Research Program (CDRMP) Breast Cancer Research Program grant (award number W81WXH21-1-0109). We acknowledge Dr. James A. Kelley (National Cancer Institute) for providing the high-resolution mass spectrometry analysis. We thank Dr. Gary T. Pauly (National Cancer Institute) for assisting with LC/MS and HPLC purification. The Biophysics Resource, CCR is acknowledged for use of instrumentation. We would also like to thank Dr. Jeff Carrell (CCR-Frederick Flow Cytometry Core Laboratory) for assisting with flow cytometry and Dr. Elijah F. Edmondson (Molecule Histopathology Laboratory, Leidos Biomedical Research) for ex vivo analyzing histopathology samples.

\section{REFERENCES}

1. Joshi, B. P.; Wang, T. D., Targeted Optical Imaging Agents in Cancer: Focus on Clinical Applications. Contrast Media Mol Imaging 2018, 2018, 2015237.

2. Rosenthal, E. L.; Warram, J. M.; de Boer, E.; Chung, T. K.; Korb, M. L.; Brandwein-Gensler, M.; Strong, T. V.; Schmalbach, C. E.; Morlandt, A. B.; Agarwal, G.; Hartman, Y. E.; Carroll, W. R.; Richman, J. S.; Clemons, L. K.; Nabell, L. M.; Zinn, K. R., Safety and Tumor Specificity of CetuximabIRDye800 for Surgical Navigation in Head and Neck Cancer. Clin Cancer Res 2015, 21 (16), 3658-66.

3. $\quad$ Chari, R. V.; Miller, M. L.; Widdison, W. C., Antibody-drug conjugates: an emerging concept in cancer therapy. Angewandte Chemie 2014, 53 (15), 3796-827.

4. Usama, S. M.; Thapaliya, E. R.; Luciano, M. P.; Schnermann, M. J., Not so innocent: Impact of fluorophore chemistry on the in vivo properties of bioconjugates. Curr Opin Chem Biol 2021, 63, 38-45.

5. Donaghy, H., Effects of antibody, drug and linker on the preclinical and clinical toxicities of antibody-drug conjugates. Mabs-Austin 2016, 8 (4), 659-71.

6. Buecheler, J. W.; Winzer, M.; Weber, C.; Gieseler, H., Alteration of Physicochemical Properties for Antibody-Drug Conjugates and Their Impact on Stability. J Pharm Sci 2020, 109 (1), 161-168.

7. Agarwal, P.; Bertozzi, C. R., Site-specific antibody-drug conjugates: the nexus of bioorthogonal chemistry, protein engineering, and drug development. Bioconjug Chem 2015, 26 (2), 176-92.

8. Panowski, S.; Bhakta, S.; Raab, H.; Polakis, P.; Junutula, J. R., Site-specific antibody drug conjugates for cancer therapy. Mabs-Austin 2014, 6 (1), 34-45.

9. Sochaj, A. M.; Swiderska, K. W.; Otlewski, J., Current methods for the synthesis of homogeneous antibody-drug conjugates. Biotechnol Adv 2015, 33 (6), 775-784.

10. Ernst, L. A.; Gupta, R. K.; Mujumdar, R. B.; Waggoner, A. S., Cyanine dye labeling reagents for sulfhydryl groups. Cytometry 1989, 10 (1), 3-10.

11. Nani, R. R.; Shaum, J. B.; Gorka, A. P.; Schnermann, M. J., Electrophile-Integrating Smiles Rearrangement Provides Previously Inaccessible C4'-O-Alkyl Heptamethine Cyanine Fluorophores. Organic Letters 2015, 17 (2), 302-305.

12. Sato, K.; Nagaya, T.; Nakamura, Y.; Harada, T.; Nani, R. R.; Shaum, J. B.; Gorka, A. P.; Kim, I.; Paik, C. H.; Choyke, P. L.; Schnermann, M. J.; Kobayashi, H., Impact of C4'-O-Alkyl Linker on in 
Vivo Pharmacokinetics of Near-Infrared Cyanine/Monoclonal Antibody Conjugates. Molecular Pharmaceutics 2015, 12 (9), 3303-3311.

13. Sato, K.; Gorka, A. P.; Nagaya, T.; Michie, M. S.; Nakamura, Y.; Nani, R. R.; Coble, V. L.; Vasalatiy, O. V.; Swenson, R. E.; Choyke, P. L.; Schnermann, M. J.; Kobayashi, H., Effect of charge localization on the: In vivo optical imaging properties of near-infrared cyanine dye/monoclonal antibody conjugates. Molecular BioSystems 2016, 12 (10), 3046-3056.

14. Sato, K.; Gorka, A. P.; Nagaya, T.; Michie, M. S.; Nani, R. R.; Nakamura, Y.; Coble, V. L.; Vasalatiy, O. V.; Swenson, R. E.; Choyke, P. L.; Schnermann, M. J.; Kobayashi, H., Role of Fluorophore Charge on the in Vivo Optical Imaging Properties of Near-Infrared Cyanine Dye/Monoclonal Antibody Conjugates. Bioconjugate Chemistry 2016, 27 (2), 404-413.

15. Cha, J.; Nani, R. R.; Luciano, M. P.; Kline, G.; Broch, A.; Kim, K.; Namgoong, J. M.; Kulkarni, R. A.; Meier, J. L.; Kim, P.; Schnermann, M. J., A chemically stable fluorescent marker of the ureter. Bioorganic and Medicinal Chemistry Letters 2018, 28 (16), 2741-2745.

16. Luciano, M. P.; Crooke, S. N.; Nourian, S.; Dingle, I.; Nani, R. R.; Kline, G.; Patel, N. L.; Robinson, C. M.; Difilippantonio, S.; Kalen, J. D.; Finn, M. G.; Schnermann, M. J., A Nonaggregating Heptamethine Cyanine for Building Brighter Labeled Biomolecules. ACS Chemical Biology 2019, 14 (5), 934-940.

17. Li, D.-H.; Schreiber, C. L.; Smith, B. D., Sterically Shielded Heptamethine Cyanine Dyes for Bioconjugation and High Performance Near-Infrared Fluorescence Imaging. Angewandte Chemie International Edition 2020, 59 (29), 12154-12161.

18. Yazaki, P.; Lwin, T.; Minnix, M.; Li, L.; Sherman, A.; Molnar, J.; Miller, A.; Frankel, P.; Chea, J.; Poku, E.; Bowles, N.; Hoffman, R.; Shively, J.; Bouvet, M., Improved antibody-guided surgery with a near-infrared dye on a PEGylated linker for CEA-positive tumors. Journal of Biomedical Optics 2019, 24 (6), 066012.

19. Rodell, C. B.; Baldwin, P.; Fernandez, B.; Weissleder, R.; Sridhar, S.; Dubach, J. M., Quantification of Cellular Drug Biodistribution Addresses Challenges in Evaluating in vitro and in vivo Encapsulated Drug Delivery. Adv Ther (Weinh) 2021, 4 (3).

20. Thurber, G. M.; Yang, K. S.; Reiner, T.; Kohler, R. H.; Sorger, P.; Mitchison, T.; Weissleder, R., Single-cell and subcellular pharmacokinetic imaging allows insight into drug action in vivo. Nat Commun 2013, 4, 1504.

21. Cilliers, C.; Menezes, B.; Nessler, I.; Linderman, J.; Thurber, G. M., Improved Tumor Penetration and Single-Cell Targeting of Antibody-Drug Conjugates Increases Anticancer Efficacy and Host Survival. Cancer Res 2018, 78 (3), 758-768.

22. Simmons, J. K.; Burke, P. J.; Cochran, J. H.; Pittman, P. G.; Lyon, R. P., Reducing the antigenindependent toxicity of antibody-drug conjugates by minimizing their non-specific clearance through PEGylation. Toxicol Appl Pharmacol 2020, 392, 114932.

23. Lyon, R. P.; Bovee, T. D.; Doronina, S. O.; Burke, P. J.; Hunter, J. H.; Neff-LaFord, H. D.; Jonas, M.; Anderson, M. E.; Setter, J. R.; Senter, P. D., Reducing hydrophobicity of homogeneous antibody-drug conjugates improves pharmacokinetics and therapeutic index. Nat Biotechnol 2015, 33 (7), 733-5.

24. Zhao, R. Y.; Wilhelm, S. D.; Audette, C.; Jones, G.; Leece, B. A.; Lazar, A. C.; Goldmacher, V. S.; Singh, R.; Kovtun, Y.; Widdison, W. C.; Lambert, J. M.; Chari, R. V., Synthesis and evaluation of hydrophilic linkers for antibody-maytansinoid conjugates. J Med Chem 2011, 54 (10), 3606-23.

25. Moon, S. J.; Govindan, S. V.; Cardillo, T. M.; D'Souza, C. A.; Hansen, H. J.; Goldenberg, D. M., Antibody conjugates of 7-ethyl-10-hydroxycamptothecin (SN-38) for targeted cancer chemotherapy. $J$ Med Chem 2008, 51 (21), 6916-26.

26. Miller, M. L.; Roller, E. E.; Zhao, R. Y.; Leece, B. A.; Ab, O.; Baloglu, E.; Goldmacher, V. S.; Chari, R. V., Synthesis of taxoids with improved cytotoxicity and solubility for use in tumor-specific delivery. J Med Chem 2004, 47 (20), 4802-5.

27. King, H. D.; Dubowchik, G. M.; Mastalerz, H.; Willner, D.; Hofstead, S. J.; Firestone, R. A.; Lasch, S. J.; Trail, P. A., Monoclonal antibody conjugates of doxorubicin prepared with branched peptide 
linkers: inhibition of aggregation by methoxytriethyleneglycol chains. $J$ Med Chem 2002, 45 (19), 433643.

28. Gruber, H. J.; Hahn, C. D.; Kada, G.; Riener, C. K.; Harms, G. S.; Ahrer, W.; Dax, T. G.; Knaus, H. G., Anomalous fluorescence enhancement of $\mathrm{Cy} 3$ and cy3.5 versus anomalous fluorescence loss of $\mathrm{Cy} 5$ and $\mathrm{Cy} 7$ upon covalent linking to IgG and noncovalent binding to avidin. Bioconjug Chem 2000, $11(5), 696-704$.

29. Pauli, J.; Grabolle, M.; Brehm, R.; Spieles, M.; Hamann, F. M.; Wenzel, M.; Hilger, I.; ReschGenger, U., Suitable labels for molecular imaging--influence of dye structure and hydrophilicity on the spectroscopic properties of IgG conjugates. Bioconjug Chem 2011, 22 (7), 1298-308.

30. Pauli, J.; Pochstein, M.; Haase, A.; Napp, J.; Luch, A.; Resch-Genger, U., Influence of Label and Charge Density on the Association of the Therapeutic Monoclonal Antibodies Trastuzumab and Cetuximab Conjugated to Anionic Fluorophores. Chembiochem 2017, 18 (1), 101-110.

31. Rijpkema, M.; Bos, D. L.; Cornelissen, A. S.; Franssen, G. M.; Goldenberg, D. M.; Oyen, W. J.; Boerman, O. C., Optimization of Dual-Labeled Antibodies for Targeted Intraoperative Imaging of Tumors. Mol Imaging 2015, 14, 348-55.

32. Cohen, R.; Stammes, M. A.; de Roos, I. H.; Stigter-van Walsum, M.; Visser, G. W.; van Dongen, G. A., Inert coupling of IRDye $800 \mathrm{CW}$ to monoclonal antibodies for clinical optical imaging of tumor targets. EJNMMI Res 2011, 1 (1), 31.

33. Conner, K. P.; Rock, B. M.; Kwon, G. K.; Balthasar, J. P.; Abuqayyas, L.; Wienkers, L. C.; Rock, D. A., Evaluation of near infrared fluorescent labeling of monoclonal antibodies as a tool for tissue distribution. Drug Metab Dispos 2014, 42 (11), 1906-13.

34. Burke, P. J.; Hamilton, J. Z.; Jeffrey, S. C.; Hunter, J. H.; Doronina, S. O.; Okeley, N. M.; Miyamoto, J. B.; Anderson, M. E.; Stone, I. J.; Ulrich, M. L.; Simmons, J. K.; McKinney, E. E.; Senter, P. D.; Lyon, R. P., Optimization of a PEGylated Glucuronide-Monomethylauristatin E Linker for AntibodyDrug Conjugates. Mol Cancer Ther 2017, 16 (1), 116-123.

35. Mujumdar, R. B.; Ernst, L. A.; Mujumdar, S. R.; Lewis, C. J.; Waggoner, A. S., Cyanine Dye Labeling Reagents - Sulfoindocyanine Succinimidyl Esters. Bioconjugate Chemistry 1993, 4 (2), 105-111.

36. Mujumdar, S. R.; Mujumdar, R. B.; Grant, C. M.; Waggoner, A. S., Cyanine-labeling reagents: Sulfobenzindocyanine succinimidyl esters. Bioconjugate Chem 1996, 7 (3), 356-362.

37. Longmire, M.; Choyke, P. L.; Kobayashi, H., Clearance properties of nano-sized particles and molecules as imaging agents: considerations and caveats. Nanomedicine (Lond) 2008, 3 (5), 703-17.

38. Meyer, D. W.; Bou, L. B.; Shum, S.; Jonas, M.; Anderson, M. E.; Hamilton, J. Z.; Hunter, J. H.; Wo, S. W.; Wong, A. O.; Okeley, N. M.; Lyon, R. P., An in Vitro Assay Using Cultured Kupffer Cells Can Predict the Impact of Drug Conjugation on in Vivo Antibody Pharmacokinetics. Mol Pharm 2020, 17 (3), 802-809.

39. Seaman, S.; Zhu, Z.; Saha, S.; Zhang, X. M.; Yang, M. Y.; Hilton, M. B.; Morris, K.; Szot, C.; Morris, H.; Swing, D. A.; Tessarollo, L.; Smith, S. W.; Degrado, S.; Borkin, D.; Jain, N.; Scheiermann, J.; Feng, Y.; Wang, Y.; Li, J.; Welsch, D.; DeCrescenzo, G.; Chaudhary, A.; Zudaire, E.; Klarmann, K. D.; Keller, J. R.; Dimitrov, D. S.; St Croix, B., Eradication of Tumors through Simultaneous Ablation of CD276/B7-H3-Positive Tumor Cells and Tumor Vasculature. Cancer Cell 2017, 31 (4), 501-515 e8.

40. Kendsersky, N. M.; Lindsay, J.; Kolb, E. A.; Smith, M. A.; Teicher, B. A.; Erickson, S. W.; Earley, E. J.; Mosse, Y. P.; Martinez, D.; Pogoriler, J.; Krytska, K.; Patel, K.; Groff, D.; Tsang, M.; Ghilu, S.; Wang, Y.; Seaman, S.; Feng, Y.; Croix, B. S.; Gorlick, R.; Kurmasheva, R.; Houghton, P. J.; Maris, J. M., The B7-H3-Targeting Antibody-Drug Conjugate m276-SL-PBD Is Potently Effective Against Pediatric Cancer Preclinical Solid Tumor Models. Clin Cancer Res 2021, 27 (10), 2938-2946.

41. Qin, X.; Zhang, H.; Ye, D.; Dai, B.; Zhu, Y.; Shi, G., B7-H3 is a new cancer-specific endothelial marker in clear cell renal cell carcinoma. Onco Targets Ther 2013, 6, 1667-73.

42. Zang, X.; Sullivan, P. S.; Soslow, R. A.; Waitz, R.; Reuter, V. E.; Wilton, A.; Thaler, H. T.; Arul, M.; Slovin, S. F.; Wei, J.; Spriggs, D. R.; Dupont, J.; Allison, J. P., Tumor associated endothelial expression of B7-H3 predicts survival in ovarian carcinomas. Mod Pathol 2010, 23 (8), 1104-12. 
43. Brunner, A.; Hinterholzer, S.; Riss, P.; Heinze, G.; Brustmann, H., Immunoexpression of B7-H3 in endometrial cancer: relation to tumor T-cell infiltration and prognosis. Gynecol Oncol 2012, 124 (1), 105-11.

44. Seaman, S.; Stevens, J.; Yang, M. Y.; Logsdon, D.; Graff-Cherry, C.; St Croix, B., Genes that distinguish physiological and pathological angiogenesis. Cancer Cell 2007, 11 (6), 539-54.

45. Choi, H. S.; Nasr, K.; Alyabyev, S.; Feith, D.; Lee, J. H.; Kim, S. H.; Ashitate, Y.; Hyun, H.; Patonay, G.; Strekowski, L.; Henary, M.; Frangioni, J. V., Synthesis and In Vivo Fate of Zwitterionic Near-Infrared Fluorophores. Angew Chem Int Edit 2011, 50 (28), 6258-6263.

46. Boswell, C. A.; Tesar, D. B.; Mukhyala, K.; Theil, F. P.; Fielder, P. J.; Khawli, L. A., Effects of charge on antibody tissue distribution and pharmacokinetics. Bioconjug Chem 2010, 21 (12), 2153-63.

47. Lee, H. J.; Pardridge, W. M., Monoclonal antibody radiopharmaceuticals: cationization, pegylation, radiometal chelation, pharmacokinetics, and tumor imaging. Bioconjug Chem 2003, 14 (3), 54653.

48. Lee, W.; Bobba, K. N.; Kim, J. Y.; Park, H.; Bhise, A.; Kim, W.; Lee, K.; Rajkumar, S.; Nam, B.; Lee, K. C.; Lee, S. H.; Ko, S.; Lee, H. J.; Jung, S. T.; Yoo, J., A short PEG linker alters the in vivo pharmacokinetics of trastuzumab to yield high-contrast immuno-PET images. J Mater Chem B 2021, 9 (13), 2993-2997.

49. Guillou, A.; Earley, D. F.; Klingler, S.; Nisli, E.; Nuesch, L. J.; Fay, R.; Holland, J. P., The Influence of a Polyethylene Glycol Linker on the Metabolism and Pharmacokinetics of a (89)ZrRadiolabeled Antibody. Bioconjug Chem 2021, 32 (7), 1263-1275.

50. Sano, K.; Nakajima, T.; Miyazaki, K.; Ohuchi, Y.; Ikegami, T.; Choyke, P. L.; Kobayashi, H., Short PEG-linkers improve the performance of targeted, activatable monoclonal antibody-indocyanine green optical imaging probes. Bioconjug Chem 2013, 24 (5), 811-6.

51. Chapman, A. P., PEGylated antibodies and antibody fragments for improved therapy: a review. Adv Drug Deliv Rev 2002, 54 (4), 531-45.

52. Gokarn, Y. R.; McLean, M.; Laue, T. M., Effect of PEGylation on protein hydrodynamics. Mol Pharm 2012, 9 (4), 762-73.

53. Takashina, K.; Kitamura, K.; Yamaguchi, T.; Noguchi, A.; Noguchi, A.; Tsurumi, H.; Takahashi, T., Comparative pharmacokinetic properties of murine monoclonal antibody A7 modified with neocarzinostatin, dextran and polyethylene glycol. Jpn J Cancer Res 1991, 82 (10), 1145-50.

54. Kitamura, K.; Takahashi, T.; Yamaguchi, T.; Noguchi, A.; Noguchi, A.; Takashina, K.; Tsurumi, H.; Inagake, M.; Toyokuni, T.; Hakomori, S., Chemical engineering of the monoclonal antibody A7 by polyethylene glycol for targeting cancer chemotherapy. Cancer Res 1991, 51 (16), 4310-5.

55. Suzuki, T.; Kanbara, N.; Tomono, T.; Hayashi, N.; Shinohara, I., Physicochemical and biological properties of poly(ethylene glycol)-coupled immunoglobulin G. Biochim Biophys Acta 1984, 788 (2), 24855.

56. Elsadek, N. E.; Hondo, E.; Shimizu, T.; Takata, H.; Abu Lila, A. S.; Emam, S. E.; Ando, H.; Ishima, Y.; Ishida, T., Impact of Pre-Existing or Induced Anti-PEG IgM on the Pharmacokinetics of Peginterferon Alfa-2a (Pegasys) in Mice. Mol Pharm 2020, 17 (8), 2964-2970.

57. Yang, Q.; Lai, S. K., Anti-PEG immunity: emergence, characteristics, and unaddressed questions. Wiley Interdiscip Rev Nanomed Nanobiotechnol 2015, 7 (5), 655-77.

58. Justin T. Huckaby, T. M. J., Zhongbo Li, Robert J. Perna, Anting Wang, Nathan I. Nicely \& Samuel K. Lai, Structure of an anti-PEG antibody reveals an open ring that captures highly flexible PEG polymers. Communications Chemistry 2020.

59. Schlenoff, J. B., Zwitteration: coating surfaces with zwitterionic functionality to reduce nonspecific adsorption. Langmuir 2014, 30 (32), 9625-36.

60. Erfani, A.; Seaberg, J.; Aichele, C. P.; Ramsey, J. D., Interactions between Biomolecules and Zwitterionic Moieties: A Review. Biomacromolecules 2020, 21 (7), 2557-2573.

61. Debie, P.; Van Quathem, J.; Hansen, I.; Bala, G.; Massa, S.; Devoogdt, N.; Xavier, C.; Hernot, S., Effect of Dye and Conjugation Chemistry on the Biodistribution Profile of Near-Infrared-Labeled Nanobodies as Tracers for Image-Guided Surgery. Molecular Pharmaceutics 2017, 14 (4), 1145-1153. 
62. Luciano, M. P.; Dingle, I.; Nourian, S.; Schnermann, M. J., Preferential Light-Chain Labeling of Native Monoclonal Antibodies Improves the Properties of Fluorophore Conjugates. Tetrahedron Lett 2021, 75. 